\title{
Impact of substandard and falsified antimalarials in Zambia: application of the SAFARI model
}

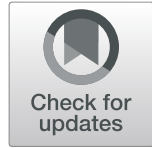

Kathryn D. Jackson', Colleen R. Higgins², Sarah K. Laing ${ }^{3}$, Chiluba Mwila, Tamaki Kobayashi, ${ }^{5,6}$, Matthew M. Ippolito ${ }^{6,7}$, Sean Sylvia ${ }^{1,8}$ and Sachiko Ozawa $2,9^{*}$ (D)

\begin{abstract}
Background: Many countries are striving to become malaria-free, but global reduction in case estimates has stagnated in recent years. Substandard and falsified medicines may contribute to this lack of progress. Zambia aims to eliminate their annual burden of 1.2 million pediatric malaria cases and 2500 child deaths due to malaria. We examined the health and economic impact of poor-quality antimalarials in Zambia.

Methods: An agent-based model, Substandard and Falsified Antimalarial Research Impact (SAFARI), was modified and applied to Zambia. The model was developed to simulate population characteristics, malaria incidence, patient care-seeking, disease progression, treatment outcomes, and associated costs of malaria for children under age five. Zambia-specific demographic, epidemiological, and cost inputs were extracted from the literature. Simulations were run to estimate the health and economic impact of poor-quality antimalarials, the effect of potential artemisinin resistance, and six additional malaria focused policy interventions.

Results: We simulated annual malaria cases among Zambian children under five. At baseline, we found 2610 deaths resulting in $\$ 141.5$ million in annual economic burden of malaria. We estimated that elimination of substandard and falsified antimalarials would result in an $8.1 \%(n=213)$ reduction in under-five deaths, prevent 937 hospitalizations, and realize $\$ 8.5$ million in economic savings, annually. Potential artemisinin resistance could further increase deaths by $6.3 \%(n=166)$ and cost an additional $\$ 9.7$ million every year.

Conclusions: Eliminating substandard and falsified antimalarials is an important step towards a malaria-free Zambia. Beyond the dissemination of insecticide-treated bed nets, indoor residual spraying, and other malaria control measures, attention must also be paid to assure the quality of antimalarial treatments.
\end{abstract}

Keywords: Malaria, Antimalarials, Substandard, Falsified, Zambia, Quality

\footnotetext{
* Correspondence: ozawa@unc.edu

${ }^{2}$ Division of Practice Advancement and Clinical Education, UNC Eshelman

School of Pharmacy, University of North Carolina, CB\#7574, Beard Hall, 115H, Chapel Hill, NC 27599, USA

${ }^{9}$ Department of Maternal and Child Health, UNC Gillings School of Global

Public Health, University of North Carolina, Chapel Hill, NC, USA

Full list of author information is available at the end of the article
}

(c) The Author(s). 2020 Open Access This article is licensed under a Creative Commons Attribution 4.0 International License, which permits use, sharing, adaptation, distribution and reproduction in any medium or format, as long as you give appropriate credit to the original author(s) and the source, provide a link to the Creative Commons licence, and indicate if changes were made. The images or other third party material in this article are included in the article's Creative Commons licence, unless indicated otherwise in a credit line to the material. If material is not included in the article's Creative Commons licence and your intended use is not permitted by statutory regulation or exceeds the permitted use, you will need to obtain permission directly from the copyright holder. To view a copy of this licence, visit http://creativecommons.org/licenses/by/4.0/ The Creative Commons Public Domain Dedication waiver (http://creativecommons.org/publicdomain/zero/1.0/) applies to the data made available in this article, unless otherwise stated in a credit line to the data. 


\section{Background}

Significant strides have been made to reduce the burden of malaria worldwide; yet global progress has stagnated in recent years [1]. The World Health Organization (WHO) estimates that nearly half of the world's population is at risk for malaria, where children under age five are the most vulnerable to the disease [2].

In Zambia, an estimated 2.7 million cases of malaria due to Plasmodium falciparum ( $P$. falciparum) occurred in 2018 [3]. Malaria disproportionately affects Zambian children under five with around 1.2 million pediatric cases and 2500 children dying annually [3-6]. Since 2006, the Zambian government has made a concerted effort to reduce the incidence of malaria. The burden of malaria declined until 2009, after which there was an annual increase in the number of estimated cases until 2015, when it started to fall again [1]. In 2017, Zambia launched its National Malaria Elimination Strategic Plan with the goal of a malaria-free Zambia by 2021 [6].

A key component of Zambia's current multifaceted approach is to provide access to quality-assured antimalarial medicines [6], which are prequalified by the WHO prequalification programme or authorized for use by the Zambia Medicines Regulatory Authority (ZAMRA) [7]. However, not all outlets where antimalarials are procured stock solely quality-assured products [8]. In 2008, less than $5 \%$ of public facilities in Zambia were stocking non-quality assured artemisinin-based combination therapies (ACTs) [9]. Yet by 2014, non-quality assured medications rose to make up $31.6 \%$ of antimalarials stocked in public facilities in Zambia [8]. This leaves room for potential sale and purchase of substandard and falsified medicines or degradation of non-quality-assured products.

As defined by the WHO and for the purposes of this paper, substandard medicines are "authorized medical products that fail to meet either quality standards, specifications, or both," and falsified medicines are medical products that "deliberately or fraudulently misrepresent their identity, composition, or source" [10]. Consuming substandard or falsified antimalarials can harm patients, leading to longer duration of illness, higher probability of severity, and greater selection for antimicrobial resistance. The economic consequences of these health effects impact patients through loss of income and payments for care induced by poor-quality medicines, and affect society through loss of productivity of patients who die prematurely or suffer from disability [11].

A recent meta-analysis revealed that $19.1 \%$ of antimalarials in low- and middle-income countries (LMICs) were substandard or falsified [12]. However, data specific to the prevalence of substandard and falsified antimalarials in many LMICs is minimal, making the use of simulation modeling important in understanding and assessing the burden resulting from use of these products. In a review of six sub-Saharan African nations not including Zambia, the WHO found that $28.5 \%$ of antimalarial samples were non-complaint with quality specifications (with non-extreme and extreme deviations) and $11.6 \%$ of antimalarials were found to have extreme deviations $[13,14]$. In Zambia, one study found that $10.3 \%$ of antimalarials tested contained less than $80 \%$ of the labeled active pharmaceutical ingredient [15]. Moreover, through post-market surveillance at hospitals in three provinces, ZAMRA found in 2019 that 22 of 125 (17.6\%) essential medicine samples including antimalarials did not pass the Global Pharma Health Fund's Minilab tests $[16,17]$.

Previous analyses across Sub-Saharan Africa found that deaths due to substandard and falsified antimalarials comprise between 3.8 and $8.9 \%$ of malaria deaths relating to cases seeking treatment [18]. Country level analyses have demonstrated that substandard and falsified antimalarials contribute substantially to the pediatric malaria burden in both Nigeria and Uganda [19, 20]. While existing literature on antimalarials in Zambia emphasizes the cost-effectiveness of treating malaria with ACTs [21], to the best of our knowledge no study has yet examined the economic impact of substandard and falsified antimalarials in Zambia. This study attempts to understand the health and economic impact due to consumption of substandard and falsified antimalarials by children in Zambia.

\section{Methods}

\section{Agent-based model simulation}

The Substandard and Falsified Antimalarial Research Impact (SAFARI) model was developed to estimate the health and economic impact of substandard and falsified antimalarials among children under five by simulating population characteristics, malaria incidence, patient care-seeking, disease progression, treatment outcomes, and associated costs $[19,20,22]$. The SAFARI model is an agent-based model implemented in Python. We developed the SAFARI model and have applied it to other countries in Sub-Saharan Africa in the past [19, 20, 22]. Methods underscoring the SAFARI model have been published previously [19]. We outline the key methods here, with descriptions of the alterations and assumptions made for the Zambian context. The main demographic, epidemiological, and cost inputs are presented in Table 1.

A flow diagram in Fig. 1 depicts the movement of child agents through the SAFARI model for Zambia. The model simulates 25,000 child agents over a one-year time horizon accounting for care-seeking and average duration of symptoms. The model is run in five-day increments to match the reported average duration of an 
Table 1 SAFARI Model Inputs for Zambia

\begin{tabular}{|c|c|c|c|}
\hline Model Input & Point Estimate & Range/SD & Source \\
\hline \multicolumn{4}{|l|}{ Demographic \& Epidemiological Data } \\
\hline$<5$ Population At Risk & $2,750,360$ & & President's Malaria Initiative 2019 [6] \\
\hline Untreated Case Progression to Severe & 0.13 & $0.07-0.30$ & Lubell 2011 [23] \\
\hline Treatment Failure Progression to Severe & 0.02 & & Lubell 2011 [23] \\
\hline Inpatient Case Fatality Rate & 0.08 & & Camponovo 2017 [24] \\
\hline Case Fatality Rate Outside of Hospital & 0.15 & & Camponovo 2017 [24] \\
\hline Inpatient Severe Case Rate of NS & 0.032 & 0.0014 & Lubell 2011 [23] \\
\hline \multicolumn{4}{|l|}{ Care-Seeking Behavior (\%) } \\
\hline Public Facilities & $67.5 \%$ & & Zambian DHS 2018 [25] \\
\hline Private Facilities & $4.6 \%$ & & Zambian DHS 2018 [25] \\
\hline Pharmacies & $0.3 \%$ & & Zambian DHS 2018 [25] \\
\hline Drug Stores & $0.8 \%$ & & Zambian DHS 2018 [25] \\
\hline CHWs & $3.0 \%$ & & Zambian DHS 2018 [25] \\
\hline Self/Neighbors & $9.2 \%$ & & Zambian DHS 2018 [25] \\
\hline No Treatment & $14.6 \%$ & & Zambian DHS 2018 [25] \\
\hline \multicolumn{4}{|l|}{ Probability facility has antimalarial in stock } \\
\hline Public Facilities & $99.8 \%$ & & ACTwatch 2014 [8] \\
\hline Private Facilities & $90.5 \%$ & & ACTwatch 2014 [8] \\
\hline Pharmacies & $88.8 \%$ & & ACTwatch 2014 [8] \\
\hline Drug Stores & $92.1 \%$ & & ACTwatch 2014 [8] \\
\hline \multicolumn{4}{|l|}{ Medication Effectiveness } \\
\hline ACTs Effectiveness & 0.962 & 0.044 & $\begin{array}{l}\text { Nambozi 2011, Bassat 2009, 4ABC 2011, } \\
\text { Hamainza 2014, Pekyi 2016, Chanda } \\
\text { 2006, Depoortere } 2005 \text { [26-32] }\end{array}$ \\
\hline SP Effectiveness & 0.759 & $0.741-0.905$ & Depoortere 2005 [31] \\
\hline Other Drug Effectiveness & 0.88 & 0.041 & Yeka 2013, Verret $2011[33,34]$ \\
\hline \multicolumn{4}{|l|}{ Substandard and Falsified Parameters } \\
\hline Proportion of SF Antimalarials (API > 85\%) & 0.103 & & Bate 2010 [15] \\
\hline $\begin{array}{l}\text { Increase in Probability of Transitioning to } \\
\text { Severe Malaria if Receive SF Drug }\end{array}$ & $50 \%$ & & Assumption \\
\hline Treatment Adherence & & Coefficient & \\
\hline Good: Probably Adherent & 0.3940 & 1 & Depoortere 2004 [35] \\
\hline Fair: Perhaps Not Adherent & 0.3940 & 0.5 & Depoortere 2004 [35] \\
\hline Poor: Definitely Not Adherent & 0.2120 & 0 & Depoortere 2004 [35] \\
\hline \multicolumn{4}{|l|}{ Patient Costs for Drugs } \\
\hline \multicolumn{4}{|l|}{ Public Facilities } \\
\hline Average Costs of ACTs & $\$ 0.00$ & & ACTwatch 2014 [8] \\
\hline Average Costs of SP & $\$ 0.00$ & & ACTwatch 2014 [8] \\
\hline Average Costs of Other Treatments & $\$ 0.00$ & & ACTwatch 2014 [8] \\
\hline \multicolumn{4}{|l|}{ Private Facilities } \\
\hline Average Costs of ACTs & $\$ 5.23$ & $\$ 2.09-\$ 12.81$ & ACTwatch 2014 [8] \\
\hline Average Costs of SP & $\$ 0.65$ & $\$ 0.33-\$ 1.96$ & ACTwatch 2014 [8] \\
\hline Average Costs of Other Treatments & $\$ 5.23$ & $\$ 0.00-\$ 8.24$ & ACTwatch 2014 [8] \\
\hline \multicolumn{4}{|l|}{ Pharmacies } \\
\hline Average Costs of ACTs & $\$ 5.23$ & $\$ 3.92-\$ 7.85$ & ACTwatch 2014 [8] \\
\hline
\end{tabular}


Table 1 SAFARI Model Inputs for Zambia (Continued)

\begin{tabular}{|c|c|c|c|}
\hline Model Input & Point Estimate & Range/SD & Source \\
\hline Average Costs of SP & $\$ 0.33$ & $\$ 0.26-\$ 0.65$ & ACTwatch 2014 [8] \\
\hline Average Costs of Other Treatments & $\$ 5.49$ & $\$ 3.84-\$ 5.49$ & ACTwatch 2014 [8] \\
\hline \multicolumn{4}{|l|}{ Drug Stores } \\
\hline Average Costs of ACTs & $\$ 1.96$ & $\$ 1.31-\$ 3.14$ & ACTwatch 2014 [8] \\
\hline Average Costs of SP & $\$ 0.39$ & $\$ 0.26-\$ 0.39$ & ACTwatch 2014 [8] \\
\hline Average Costs of Other Treatments & $\$ 1.37$ & $\$ 0.00-\$ 0.00$ & ACTwatch 2014 [8] \\
\hline \multicolumn{4}{|l|}{ Other Costs to Patients } \\
\hline Transport Costs (Public, Private) & $\$ 2.51$ & $\$ 1.25-\$ 6.26$ & Aspler 2008 [36] \\
\hline Transport Costs (Pharmacies, Drug Stores) & $\$ 0.25$ & & Assumption based on: Aspler 2008 [36] \\
\hline Costs of Special Food for Children & $\$ 3.12$ & $\$ 0.96-\$ 6.26$ & Aspler 2008 [36] \\
\hline Costs per Pediatric Malaria Hospitalization & $\$ 10.56$ & $\$ 2.69$ & WHO CHOICE 2010 [37] \\
\hline Productivity Loss per Sick Day & $\$ 3.21$ & & Calculation based on World Bank 2019 [38] \\
\hline Productivity Loss from Death, Discounted at 3\% & $\$ 30,155.30$ & & Calculation based on World Bank 2019 [38] \\
\hline NS Disability Productivity Loss, Discounted at 3\% & $\$ 12,477.37$ & & Calculation based on World Bank 2019 [38] \\
\hline \multicolumn{4}{|l|}{ Facility Costs } \\
\hline Facility Costs per Testing & $\$ 0.96$ & $\$ 0.21$ & Chanda 2009 [39] \\
\hline Facility Costs per ACTs & $\$ 2.00$ & $\$ 0.50$ & Chanda 2007 [40] \\
\hline Facility Costs per SP & $\$ 0.27$ & $\$ 0.06$ & Chanda 2007 [40] \\
\hline Facility Costs per Other Treatments & $\$ 0.11$ & & Calculation \\
\hline Public Facility Costs per Consultation & $\$ 6.40$ & $\$ 1.51$ & Chanda 2007 [40] \\
\hline Facility Costs per Pediatric Malaria Hospitalization & $\$ 84.07$ & $\$ 6.72$ & Comfort 2014 [41] \\
\hline Costs per CHW Treatment & $\$ 1.01$ & $\$ 0.19$ & Chanda 2011 [42] \\
\hline Costs per CHW Testing & $\$ 3.14$ & $\$ 0.79$ & Haimanza 2014 [43] \\
\hline Costs per CHW Visit & $\$ 3.32$ & $\$ 0.79$ & Chanda 2011 [42] \\
\hline
\end{tabular}

ACTs artemisinin-based combination therapies, API active pharmaceutical ingredient, $C H W$ s community health workers, DHS demographic and health survey, NS neurologic sequelae, SD standard deviation, SF substandard or falsified, SP sulfadoxine-pyrimethamine, WHO World Health Organization

uncomplicated $P$. falciparum malaria case. All child agents begin healthy and then move through the disease and care-seeking simulations. If the child agent becomes infected and symptomatic, the model simulates treatment at one of six care-seeking locations (public facility, private facility, pharmacies, drug stores, community health workers or self-medication including receiving medicines from friends/neighbors) or the progression of disease without seeking care.

Antimalarial treatment available in each location is simulated based on the market share of three medicines: ACTs, sulfadoxine-pyrimethamine (SP), or other treatments (e.g. quinine). In Zambia, $97.4 \%$ of the pediatric population receive ACTs and $1.3 \%$ receive SP and 1.3\% received another drug (quinine, chloroquine, other antimalarial) for treatment of uncomplicated malaria based on data from the Demographic and Health Survey (DHS) [25]. The recommended treatment for pediatric malaria is artemether-lumefantrine branded as Coartem, which is available for free in public facilities. We simulated that each care location could run out of stock of antimalarials using facility specific probabilities of having ACTs in stock, derived from national stock availability data from ACTwatch [8]. At the end of a five-day period, child agents who are healthy, infected and asymptomatic, or infected and symptomatic return to the start of the model. Those who have progressed to a severe case face a probability of death according to case fatality rates from the literature and are removed from the model simulation, or face a probability of suffering from neurological sequelae [23, 24].

\section{Demographic, epidemiologic, and cost data inputs}

One of the benefits of agent-based models is the ability to assign demographic characteristics, individual incidence, and individual care-seeking rates to each child agent. Demographic characteristics such as age, socioeconomic status, mother's education, urban/rural residence, and region (zones) were assigned to child agents based on the reported national prevalence in Zambia, retrieved from the 2018 Zambia DHS and the $2018 \mathrm{Mal}-$ aria Indictor Survey (MIS) [25]. Individual incidence and 


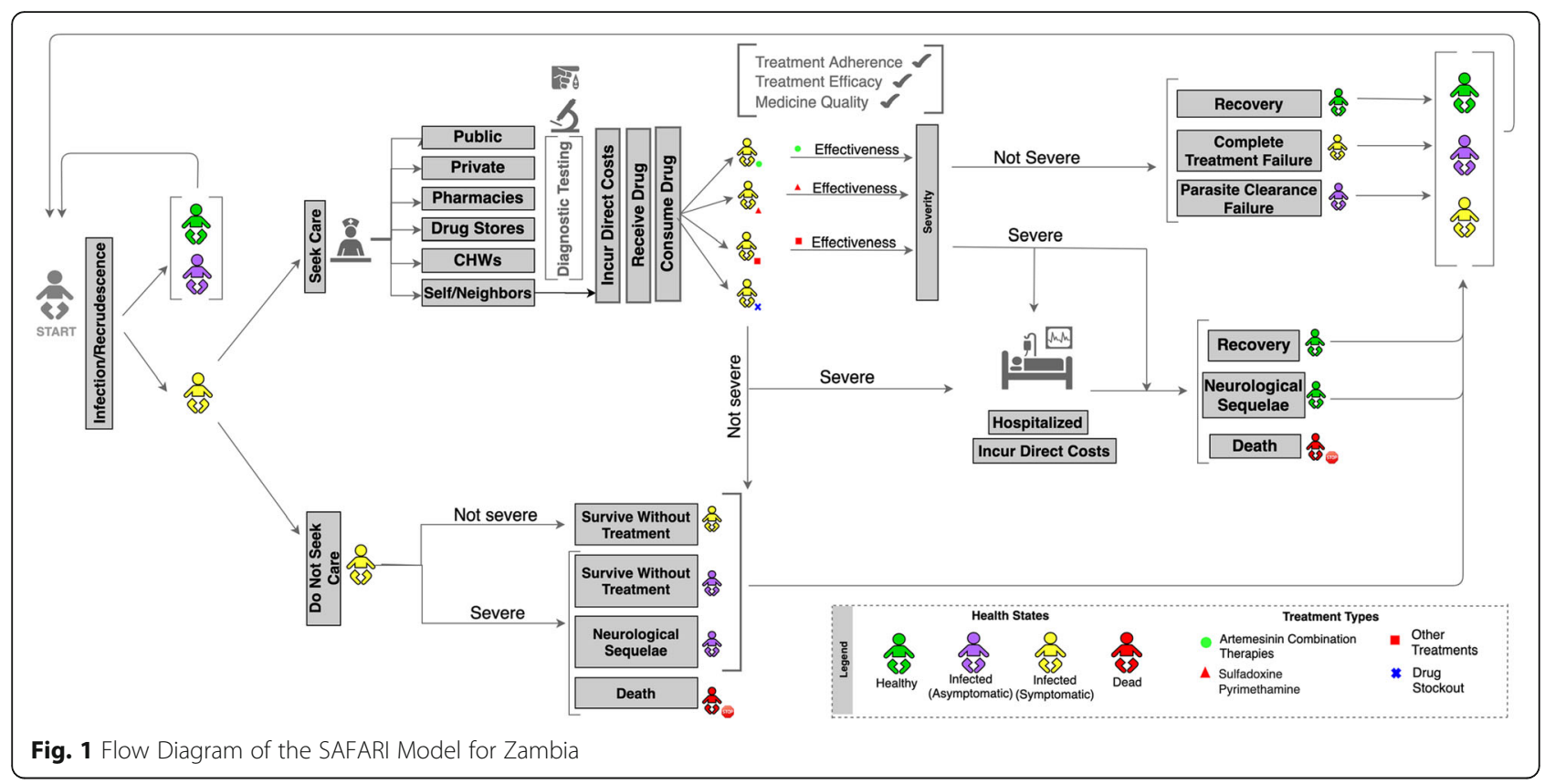

care-seeking probabilities were calculated for each child agent based on the combination of these characteristics, allowing for variation in the model and facilitating outputs to be examined on a more granular level.

Electronic databases (PubMed, Google Scholar, and EBSCOhost) were searched for published literature related to antimalarials, medicine quality, pediatric malaria, and costs of care to identify model inputs specific to Zambia. Gray literature was used to isolate additional inputs from sources such as ACTwatch, the Zambia DHS/MIS, the World Malaria Report, and the Worldwide Antimalarial Resistance Network (WWARN) [1, 8, 25, 44]. In order to account for the natural variation in epidemiologic and cost inputs, these inputs were sampled from specified distributions using means and standard deviations from the literature across 10,000 model runs. Cost inputs were ranged across beta distributions and epidemiological inputs were ranged using gamma distributions. All costs are reported in 2018 USD (\$). Costs in Zambian Kwacha were inflated from various years to 2018 Kwacha using Zambia's inflation rates and converted to 2018 USD using exchange rates from the U.S. Treasury $[45,46]$.

Treatment efficacy for each antimalarial and prevalence of substandard and falsified medicines for Zambia were obtained via the WWARN database [26-34, 44]. Due to a small number of available studies on efficacy of quinine in children under five in Zambia, regional studies were utilized for child agents who received treatments other than ACTs or SP (approximately $2.9 \%$ of cases) [32-34]. To account for the increase in adverse outcomes caused by substandard or falsified antimalarials, it was assumed that patients who received poor-quality antimalarials faced a $50 \%$ increase in the probability of developing severe malaria within a week of receiving treatment, reflecting the impact of reduced efficacy of antimalarials with lower amounts of active pharmaceutical ingredients [18]. Each child agent in the model was assigned a probability of treatment adherence, which affected treatment success [35]. Treatment outcomes for each child agent in the model were determined based on individual treatment adherence rates, treatment efficacy by medication, and quality of obtained antimalarials.

\section{Health and economic outputs}

Primary outputs of the model are estimates of the health impact, direct costs, and productivity losses attributable to substandard and falsified antimalarials among children under five in Zambia. The health impact is presented as numbers of uncomplicated and severe cases, cases of neurological sequelae, and deaths due to malaria. Economic outputs report direct costs, which include costs for transportation, testing, drugs, consultation, and hospitalization, as well as productivity losses [23, 36, 37, 39-43]. Productivity losses are calculated from Zambia's Gross Domestic Product (GDP) per capita, and are broken into shortterm losses, which include time lost by care-takers, and long-term losses over a lifetime due to children suffering from malaria-induced disabilities or premature deaths [38]. Future long-term productivity losses were discounted at $3 \%$. At public facilities, direct 
costs were further separated into those paid by patient families out-of-pocket versus those incurred by public facilities.

\section{Scenario analyses}

We analyzed the effect of substandard and falsified antimalarials among the under-five population by simulating three antimalarial quality scenarios. First, we estimated the burden of malaria in Zambia and utilized this scenario as our baseline estimate. We then isolated the effect of substandard and falsified antimalarials on the health and economic impact of malaria that is due to $10.3 \%$ prevalence of poor-quality antimalarials [15]. In order to address the uncertainty around the prevalence of substandard and falsified antimalarials, we also examined a scenario in which Zambia experienced 19.1\% prevalence of substandard and falsified antimalarials, which is the average across all LMICs [12]. These two scenarios (10.3 and $19.1 \%$ prevalence) provide a range for the possible impact of poor-quality antimalarials in the country, given the limited evidence on the prevalence of substandard and falsified antimalarials in Zambia. We additionally examined the hypothetical implications of $P$. falciparum, the parasite causing almost all malaria cases in Zambia, potentially developing resistance to ACTs. To simulate this scenario, we reduced the effectiveness of ACTs to that of less effective treatment (SP), and prolonged the illness for each child agent taking ACTs by 5 days, to reflect the increase in illness duration likely associated with antimalarial resistance [47]. This scenario was compared to the baseline scenario to estimate the additional impact of potential antimalarial resistance.

Lastly, we implemented six scenario analyses simulating proposed interventions to assess their impact on malaria outcomes in Zambia. These scenarios included: 1) no antimalarial stock-outs in any facilities; 2 ) no antimalarial stock-outs in public facilities; 3 ) no antimalarial stock-outs in private facilities; 4) replacement of other treatment alternatives with ACTs; 5 ) increasing the percentage of individuals seeking health care by $20 \%$ among those currently not seeking care; and 6) having no substandard or falsified antimalarials. Each scenario was examined separately, holding all other inputs constant as baseline, in order to understand the impact of the policy options.

\section{Results}

Findings on the health and economic impact of substandard and falsified antimalarials in Zambia are summarized in Table 2. With an under-five population of 2.8 million in Zambia [48], the baseline model simulated 1.2 million cases of malaria annually in Zambian children under five. Of the total cases, we simulated that 11 ,
071 cases (95\% confidence interval (CI) 11,039 - 11,103) resulted in hospitalizations, 295 cases (95\% CI 291-299) suffered from neurological sequelae, and 2610 cases (95\% CI 2598 - 2622) resulted in death, annually. The total estimated annual economic impact of malaria in children under-five in Zambia was \$141.5 million (95\% CI \$141.0 - \$141.9 million), with \$114.6 million (95\% CI $\$ 114.2$ - $\$ 115.0$ million) attributed to productivity losses, and \$11.7 million (95\% CI \$11.5 - \$11.9 million) in direct costs for health care.

Across 10,000 model runs, the burden of malaria attributable to substandard and falsified antimalarials was estimated at 213 (95\% CI 212-213) deaths and 937 (95\% CI 937-938) child hospitalizations every year, given a $10.3 \%$ prevalence of substandard and falsified antimalarials. In other words, if substandard and falsified antimalarials are replaced by high-quality ones, Zambia could experience an $8.2 \%$ reduction in under-five deaths (213 fewer deaths), observe a $8.5 \%$ reduction in the number of hospitalizations (937 fewer hospitalizations) and realize $\$ 8.5$ (95\% CI $\$ 8.5$ - $\$ 8.6$ ) million in total economic savings including averting direct costs to patients and the government, as well as preventing productivity losses due to death or life lived with disability.

Given the uncertainty in the prevalence of substandard and falsified medicines in Zambia, we simulated a further scenario in which the prevalence of poor-quality antimalarials in Zambia was as high as the LMIC-wide average of $19.1 \%$. In this scenario, a significantly higher health and economic impact was found to be attributable to poor-quality antimalarials. Annually, a $19.1 \%$ prevalence of substandard and falsified antimalarials would result in \$14.5 (95\% CI \$14.5 - \$14.5) million in costs, lead to 365 (95\% CI 365-366) under-five deaths, and be responsible for 1643 (95\% CI 1643 - 1644) pediatric hospitalizations.

We also examined the hypothetical impact of antimalarial resistance in Zambia. In the event that effectiveness of ACTs, the recommended treatment for malaria, is reduced to that of other treatments with less effective antimalarials (SP) and prolonged duration of illness, we simulated that Zambia would see an increase of 166 (95\% CI 165-166) deaths (6.3\%), and 1048 (95\% CI 1048-1048) under-five hospitalizations (9.5\%), annually. The resulting economic impact would be $\$ 9.7$ (95\% CI $\$ 9.6$ - \$9.7) million per year, with $\$ 7.7$ (95\% CI $\$ 7.7$ $\$ 7.7)$ million attributed to productivity losses.

Table 3 presents the results of six intervention scenarios, which improve stock-outs, antimalarial quality, and access to care. We found that removing substandard and falsified medications (assuming prevalence at 10.3\%) had the second-greatest impact, following increasing the number of children who seek care for malaria. If $20 \%$ of children who did not seek care for malaria sought care, 
Table 2 Comparison of the Health and Economic Impact of Scenarios including SF Antimalarials

\begin{tabular}{|c|c|c|c|c|c|c|c|c|}
\hline & \multicolumn{2}{|c|}{$\begin{array}{l}\text { Total Burden of Malaria with } \\
\text { an SF Prevalence at } 10.3 \%\end{array}$} & \multicolumn{2}{|c|}{$\begin{array}{l}\text { Savings by } \\
\text { eliminating } 10.3 \% \\
\text { prevalence of SF } \\
\text { Antimalarials }\end{array}$} & \multicolumn{2}{|c|}{$\begin{array}{l}\text { Total burden of SF } \\
\text { Antimalarials with SF } \\
\text { Prevalence of } 19.1 \%\end{array}$} & \multicolumn{2}{|c|}{$\begin{array}{l}\text { Antimalarial } \\
\text { Resistance Scenario }\end{array}$} \\
\hline & Burden & $95 \% \mathrm{Cl}$ & Impact & $\%$ & Impact & $\%^{\mathrm{a}}$ & Impact & $\%$ Diff. \\
\hline Average cases & $1,216,454$ & $(1,216,231-1,216,676)$ & & & & & & \\
\hline Average deaths & 2610 & $(2598-2622)$ & 213 & $8.2 \%$ & 365 & $13.2 \%$ & 166 & $6.3 \%$ \\
\hline Average hospitalizations & 11,071 & $(11,039-11,103)$ & 937 & $8.5 \%$ & 1643 & $14.0 \%$ & 1048 & $9.5 \%$ \\
\hline Average cases of NS & 295 & $(291-299)$ & 9 & $3.1 \%$ & 11 & $3.8 \%$ & 19 & $6.5 \%$ \\
\hline Total economic impact & $\$ 141,470,907$ & $(141,037,214-141,904,600)$ & $\$ 8,541,887$ & $6.0 \%$ & $\$ 14,465,329$ & $9.8 \%$ & $\$ 9,662,235$ & $6.8 \%$ \\
\hline Facility costs & $\$ 15,174,357$ & $(15,134,100-15,214,614)$ & $\$ \$ 411,098$ & $2.7 \%$ & $\$ 637,725$ & $4.1 \%$ & $\$ 1,266,646$ & $8.3 \%$ \\
\hline Out-of-pocket costs & $\$ 11,699,978$ & $(11,536,334-11,863,623)$ & $\$ 423,151$ & $3.6 \%$ & $\$ 478,061$ & $4.1 \%$ & $\$ 677,144$ & $5.8 \%$ \\
\hline Total productivity losses & $\$ 114,596,572$ & $(114,200,504-114,992,639)$ & $\$ 7,707,639$ & $6.7 \%$ & $\$ 13,349,543$ & $11.1 \%$ & $\$ 7,718,445$ & $6.7 \%$ \\
\hline Short-term productivity losses & $\$ 25,162,247$ & $(25,090,781-25,233,713)$ & $\$ 531,091$ & $2.1 \%$ & $\$ 1,021,167$ & $4.0 \%$ & $\$ 2,053,261$ & $8.2 \%$ \\
\hline Total lifetime productivity losses & $\$ 89,434,325$ & $(89,044,819-89,823,831)$ & $\$ 7,176,548$ & $8.0 \%$ & $\$ 12,328,376$ & $13.0 \%$ & $\$ 5,665,184$ & $6.3 \%$ \\
\hline
\end{tabular}

Cl confidence interval, NS neurologic sequelae, SF substandard and falsified

${ }^{a}$ Percentage of the total burden of malaria when SF prevalence is $19.1 \%$

we simulated economic savings of $\$ 12.7$ (95\% CI \$12.7 $\$ 12.7)$ million, assuming that the supply of antimalarials can rise with increased demand, maintaining the same proportion of quality-assured antimalarials. We estimated that removing stock-outs had a smaller effect than improving the quality of antimalarial medications. If stock-outs were eliminated in both the public and private sector maintaining the same proportion of qualityassured vis-à-vis non-quality assured antimalarials, this is estimated to reduce under-five deaths by $5.4 \%$ (141 fewer deaths; 95\% CI 141-141) and result in economic savings of $\$ 5.5$ (95\% CI $\$ 5.5$ - \$5.5) million annually.

\section{Discussion}

Our SAFARI model results highlight the importance of eliminating substandard and falsified antimalarials in
Zambia to reach the goal of malaria elimination by 2021 . Compared to the LMIC-wide average prevalence of substandard and falsified antimalarials (19.1\%), our results indicate that maintaining a lower prevalence $(10.3 \%)$ of substandard and falsified medicines would mean a difference of 153 lives and $\$ 5.9$ million in costs annually in Zambia. Based on the model, eliminating all substandard and falsified antimalarials in Zambia will result in an additional $\$ 8.5$ million in economic savings, 937 fewer hospitalizations, and save 213 children's lives every year.

At present, $80.6 \%$ of households in Zambia have access to at least one form of vector control, involving indoor residual spraying or insecticide-treated bed nets [5]. While vector control programs can reduce the incidence of malaria, access to quality-assured antimalarials is essential to stop the spread of disease when people acquire

Table 3 Impact of Intervention Scenarios Compared to Baseline

\begin{tabular}{|c|c|c|c|c|c|}
\hline & \multirow[t]{2}{*}{ Deaths } & \multicolumn{2}{|c|}{ Total Economic Impact } & \multicolumn{2}{|c|}{ Total Productivity Losses } \\
\hline & & Estimate & $95 \% \mathrm{Cl}$ & Estimate & $95 \% \mathrm{Cl}$ \\
\hline Baseline & 2610 & $\$ 141,470,907$ & $(141,037,214$ to $141,904,600)$ & $\$ 114,596,572$ & $(114,200,504$ to $114,992,639)$ \\
\hline No SF Antimalarials ${ }^{a}$ & -213 & $-\$ 8,541,887$ & $(-\$ 8,547,760$ to $-\$ 8,536,014)$ & $-\$ 7,707,639$ & $(-\$ 7,713,090$ to $-\$ 7,702,188)$ \\
\hline No stock-outs all outlets ${ }^{b, c}$ & -141 & $-\$ 5,471,452$ & $(-\$ 5,490,113$ to $-\$ 5,452,791)$ & $-\$ 5,092,216$ & $(-\$ 5,109,558$ to $-\$ 5,074,874)$ \\
\hline No public stock-outs ${ }^{c}$ & -69 & $-\$ 2,920,369$ & $(-\$ 2,926,294$ to $-\$ 2,914,444)$ & $-\$ 2,534,053$ & $(-\$ 2,539,559$ to $-\$ 2,528,548)$ \\
\hline No private stock-outs ${ }^{c}$ & -18 & $-\$ 729,901$ & $(-\$ 735,857$ to $-\$ 723,945)$ & $-\$ 584,179$ & $(-\$ 589,739$ to $-\$ 578,620)$ \\
\hline Only ACTs are available & 2 & $-\$ 56,718$ & $(-\$ 62,749$ to $-\$ 50,688)$ & $\$ 85,065$ & $(\$ 79,476$ to $\$ 90,654)$ \\
\hline Increase in care seeking habits ${ }^{c, e}$ & -345 & $-\$ 12,713,276$ & $(-\$ 12,719,093$ to $-\$ 12,707,459)$ & $-\$ 12,466,581$ & $(-\$ 12,471,928$ to $-\$ 12,461,234)$ \\
\hline
\end{tabular}

$A C T$ s artemisinin-based combination therapies, $\mathrm{Cl}$ confidence interval, SF substandard and falsified

${ }^{a}$ Simulated the prevalence of substandard and falsified antimalarials at $10.3 \%$

${ }^{\mathrm{b}}$ This includes public and private hospitals, pharmacies, general retailers, and drug stores

'These scenarios assumed that supply of antimalarials would increase to meet the demand, keeping the proportion of substandard and falsified antimalarials and the mix of available antimalarials the same as baseline

${ }^{\mathrm{d}}$ This scenario was not statistically significantly different from baseline given high ACT availability at $97.4 \%$

${ }^{e} 20 \%$ of those who did not seek care for child malaria were assumed to seek care 
malaria. Zambia currently uses the WHO medicine prequalification programme for quality-assured medicines [49]. ZAMRA also conducts random testing of medicines through post-market surveillance using the Global Pharma Health Fund's GPHF-Minilab kits, and removes suspected substandard or falsified medicines off the market for further testing $[16,17,50]$. Wider access and use of cost-effective detection devices for substandard and falsified medicines can mean detecting and removing poorquality antimalarials more effectively.

Zambia has succeeded in centralizing access to and incentivizing the purchase of antimalarials via public facilities, but improved surveillance methods are needed throughout the supply chain to quickly identify and remove substandard and falsified antimalarials. As a landlocked country with many borders, Zambia is especially vulnerable to importation of substandard and falsified medicines. Establishing a coordinated and strategic surveillance program can prevent harm from the use of poor-quality medical products. Surveillance in the private sector should be strengthened as patients can access antimalarials through privately-run retail stores, community pharmacies, private hospitals, and private clinics.

Our model estimates that reduction of stock-outs in the public and private sector would result in 141 fewer deaths (5.4\% reduction) and avert 133 hospitalizations (1\% reduction), assuming current proportions of quality-assured antimalarials are made available to fill the gap in supply. Stock-outs of quality-assured ACTs in the public sector can result in patients seeking medication from alternative retailers who stock cheaper medications, such as nonACTs and possibly poor-quality antimalarials [49]. Presence of unlicensed drug stores increases the risk of having poor-quality medicines in the market, as it is illegal for these stores to obtain medicines from registered wholesalers. Instead, these stores commonly acquire medicines from unregistered or cross-border vendors.

Since Zambia currently imports all of their medications, it can be challenging to meet the local demand for antimalarials. Fees charged by ZAMRA to import medicines are high - $\$ 2000$ and $\$ 2800$ per product for generic and innovator brands, respectively, and $\$ 4000$ to fast track medicine authorization. Those fees, along with the presence of sole distributorship arrangements, are perceived as barriers to increasing the supply of antimalarials and contribute to increased stock-outs [49]. Producing high-quality medication in Zambia may be one solution to this and potential policies have been put forward that seek to support the development of Zambian medicine manufacturing. This idea has traction in Zambia where four such facilities have opened in the past 3 years. Ensuring good manufacturing practices to generate quality-assured products is essential across both imported and domestically manufactured medicines.
Access to care continues to be a challenge in rural Zambia, with only $42 \%$ of caregivers reporting to seek early treatment within $24 \mathrm{~h}$ for children with fever [51]. Improving access to care is important for reducing the burden of malaria, as seeking care earlier reduces the likelihood of complications and death. Increasing careseeking by, for example, implementing Universal Health Coverage (UHC) could result in higher use of qualityassured medicines overall, if measures to assure the quality and quantity of additional medicines are also implemented. This implies that greater numbers of people will seek care through the formal system, where medicine quality could be regulated.

At the same time, increased care-seeking can put a strain on existing systems, increasing demand for medicines sought within the system, and requiring additional resources. Our simulation of increased care-seeking assumed health systems capacity exists to treat additional patients at current levels of care but that other barriers to access care remained [52]. In order to see improvements from care-seeking, availability of quality-assured medicines needs to increase accordingly. If the stock of medicines would not adjust with increases in careseeking, we would expect that the benefits of increased care-seeking would be much lower, as stock-outs would worsen. Increasing care seeking and medicine utilization in a system that is not prepared could in fact worsen medicine quality if producers lower quality to stay within profit margins [53]. Thus, the benefits of the increased care-seeking scenario would only materialize if the health system and supply of quality-assured medicines can accommodate increases in demand.

Our baseline results are similar to past estimates of under-five malaria disease burden in Zambia. Our model simulates 1.2 million under-five cases annually, which is comparable to the President's Malaria Initiative estimate that $35 \%$ of all malaria cases (3.5 million in Zambia) occur in children under five $[1,6]$. We chose to calibrate the model to the estimated number of cases from the World Malaria Report, which provides a more conservative estimate than alternatives that convert parasitic rates to case incidence [1]. Furthermore, our model estimates 2610 under-five deaths due to malaria annually, which is similar to the United Nations Children's Fund's (UNICEF) estimates of 2558 annual deaths in 2016 [4].

There are several limitations to note. First, the quality and availability of data surrounding antimalarial quality in Zambia is limited, which made it difficult to capture the heterogeneity within Zambia [54, 55]. We incorporated the most recent reliable data available at this time by conducting literature searches for model inputs. For inputs where Zambian pediatric malaria data were not available, Zambian adult inputs or pediatric inputs from neighboring countries were used. We address 
uncertainty around data inputs by probabilistically ranging variables in the model, and recording ranges across 10,000 model runs. Moreover, the prevalence of substandard and falsified medicines came from a single study in Zambia, which tested few antimalarial samples [15]. Further studies are needed to more effectively capture the current prevalence of poor-quality medicines in Zambia using rigorous sampling and testing methods. Lastly, our study focused on the economic costs of substandard and falsified medicines rather than the costs of interventions to improve supply chains or strengthen health systems. Such analyses could be helpful to estimate the cost-benefit ratios of medicine quality interventions. Despite these limitations, we believe our health and economic impact estimates are vital to raising public awareness of the effects of substandard and falsified antimalarials in Zambia.

\section{Conclusions}

The presence of substandard and falsified malaria medications worldwide along with the stagnation in malaria case reductions threaten global health security. This study shows that reduction of substandard and falsified antimalarials could substantially help Zambia reach the goal of malaria elimination. Zambia has successfully increased malaria prevention measures including the adoption of insecticide-treated bed nets and indoor residual spraying, but attention must also be paid to assuring antimalarial quality within the country. Increased funding and capacity building of ZAMRA and close coordination with the Ministry of Health is important to monitor and regulate the medicines supply chain, remove substandard and falsified antimalarials, and reduce stock-outs. Failing to do so would likely result in increases in malaria mortality and morbidity.

\section{Abbreviations \\ ACTs: Artemisinin-based Combination Therapies; DHS: Demographic and Health Survey; GDP: Gross Domestic Product; LMICs: Low- and Middle- Income Countries; MIS: Malaria Indicator Survey; SAFARI: Substandard and Falsified Antimalarial Research Impact; SP: Sulfadoxine-Pyrimethamine; UNICEF: United Nations Children's Fund; USD: United States Dollars; WHO: World Health Organization; WWARN: Worldwide Antimalarial Resistance Network}

\section{Acknowledgements}

We would like to thank Dr. Steve Taylor for his inputs for the disease model. We also thank the Global Health Economics for Pharmacy (GHEP) team at the University of North Carolina at Chapel Hill (Tatenda Yemeke, Hui-Han Chen) for their advice and support.

\section{Authors' contributions}

$\mathrm{KJ}$ compiled inputs, performed analysis, and drafted original manuscript. $\mathrm{CH}$ wrote model code, compiled and analyzed data, and drafted original manuscript. SL collected and analyzed data inputs for the model, and revised the manuscript. CM, TK, MI and SS interpreted data and revised the manuscript. SO conceptualized and supervised the work, interpreted data and drafted original manuscript. All authors read and approved the final manuscript.

\section{Funding}

National Institute of Allergy and Infectious Diseases (grant no. K23Al139343) to MMI.

\section{Availability of data and materials}

All data utilized during this study were taken from publicly available data and are included in this published article.

\section{Ethics approval and consent to participate}

Not applicable.

\section{Consent for publication}

Not applicable.

\section{Competing interests}

The authors declare that they have no competing interests.

\section{Author details}

'Department of Health Policy and Management, UNC Gillings School of Global Public Health, University of North Carolina, Chapel Hill, NC, USA.

${ }^{2}$ Division of Practice Advancement and Clinical Education, UNC Eshelman School of Pharmacy, University of North Carolina, CB\#7574, Beard Hall, 115H, Chapel Hill, NC 27599, USA. ${ }^{3}$ Duke Global Health Institute, Duke University, Durham, NC, USA. ${ }^{4}$ Department of Pharmacy, School of Health Sciences, University of Zambia, Lusaka, Zambia. ${ }^{5}$ Department of Epidemiology, Johns Hopkins Bloomberg School of Public Health, Baltimore, MD, USA. 'Malaria Research Institute, Johns Hopkins Bloomberg School of Public Health, Baltimore, MD, USA. 'Division of Clinical Pharmacology and Division of Infectious Diseases, Department of Medicine, Johns Hopkins University School of Medicine, Baltimore, MD, USA. ${ }^{8}$ Carolina Population Center, University of North Carolina, Chapel Hill, NC, USA. ${ }^{9}$ Department of Maternal and Child Health, UNC Gillings School of Global Public Health, University of North Carolina, Chapel Hill, NC, USA.

Received: 4 January 2020 Accepted: 5 May 2020

Published online: 09 July 2020

\section{References}

1. World Health Organization. World Malaria Report 2018. Geneva: World Health Organization; 2019.

2. World Health Organization. 10 Facts On Malaria. Geneva: World Health Organization; 2016. Available from: https://www.who.int/features/factfiles/ malaria/en/. Cited 2019 April 22.

3. World Health Organization. World Malaria Report 2019. Geneva: World Health Organization; 2019.

4. United Nations Children's Fund (UNICEF). Child Mortality Data: Cause of Death. New York: UNICEF; 2019. Available from: https://data.unicef.org/ topic/child-survival/under-five-mortality/\#data. Updated March 1, 2019; Cited 2019 April 22.

5. President's Malaria Initiative. Country in Focus - Zambia 2019. Available from: https://www.pmi.gov/where-we-work/country-in-focus/zambia. Cited 2019 April 15

6. President's Malaria Initiative. Zambia Malaria Operational Plan FY 2019. 2019.

7. The Global Fund. Sourcing \& Management of Health Products 2019. Available from: https://www.theglobalfund.org/en/sourcing-management/ quality-assurance/. Cited 2019 February 12.

8. ACTwatch Group. ACTwatch study reference document: the Republic of Zambia outlet survey 2014. Washington, DC: ACTwatch Group; 2015.

9. ACTwatch Group. ACTwatch Study Reference Document: The Republic of Zambia Outlet Survey 2009. Washington DC: ACTwatch Group; 2009.

10. World Health Organization. Definitions of Substandard and Falsified (SF) Medical Products. Geneva: World Health Organization; 2019. Available from: https:/www.who.int/medicines/regulation/ssffc/definitions/en/. Cited 2019 April 26.

11. Sachs J, Malaney P. The economic and social burden of malaria. Nature. 2002;415(6872):680-5.

12. Ozawa S, Evans DR, Bessias S, Haynie DG, Yemeke $T$, Laing SK, et al. Prevalence and estimated economic burden of substandard and falsified medicines in low- and middle-income countries: a systematic review and meta-analysis. JAMA Netw Open. 2018;1(4):e181662. 
13. Jitka Sabartova AT. Department of Essential Medicines and Pharmaceutical Policies, World Health Organization. In: Survey of the quality of selected antimalarial medicines circulating in six countries of sub-Saharan Africa. Geneva: World Health Organization; 2011.

14. World Health Organization. Survey of the quality of medicines identified by the UN Commission on life-saving commodities. Geneva: World Health Organization; 2016.

15. Bate R, Mooney L, Hess K. Medicine registration and medicine quality: a preliminary analysis of key cities in emerging markets. Res Rep Trop Med. 2010;1:89-93.

16. Zambia Medicines Regulatory Authority. ZAMRA conducts third rapid medicines quality verification exercises. Lusaka: Zamra; 2019. Available from: http://www.zamra.co.zm/zamra-conducts-third-rapid-medicines-qualityverification-exercises/. Cited 2019 Dec 1

17. Zambia Medicines Regulatory Authority. ZAMRA coducts rapid medicines quality verification exercises. Lusaka: Zamra; 2019. Available from: http:// www.zamra.co.zm/zamra-vonducts-rapid-medicines-quality-verificationexercises/. Cited 2019 Dec 1.

18. World Health Organization. A study on the public health and socioeconomic impact of substandard and falsified medical products. Geneva: World Health Organization; 2017. Available from https://www.who. int/medicines/regulation/ssffc/publications/se-study-sf/en/. Cited 2019 June 1.

19. Ozawa S, Evans DR, Higgins CR, Laing SK, Awor P. Development of an agent-based model to assess the impact of substandard and falsified antimalarials: Uganda case study. Malar J. 2019;18(1):5.

20. Beargie SM, Higgins CR, Evans DR, Laing SK, Erim D, Ozawa S. The economic impact of substandard and falsified antimalarial medications in Nigeria. PLoS One. 2019;14(8):e0217910.

21. Okell LC, Cairns M, Griffin JT, Ferguson NM, Tarning J, Jagoe G, et al. Contrasting benefits of different artemisinin combination therapies as firstline malaria treatments using model-based cost-effectiveness analysis. Nat Commun. 2014:5:5606

22. Ozawa S, Haynie DG, Bessias S, Laing SK, Ngamasana EL, Yemeke TT, et al. Modeling the economic impact of substandard and falsified Antimalarials in the Democratic Republic of the Congo. Am J Trop Med Hyg. 2019;100(5): 1149-57.

23. Lubell Y, Riewpaiboon A, Dondorp AM, von Seidlein L, Mokuolu OA, Nansumba M, et al. Cost-effectiveness of parenteral artesunate for treating children with severe malaria in sub-Saharan Africa. Bull World Health Organ. 2011;89(7):504-12.

24. Camponovo F, Bever CA, Galactionova K, Smith T, Penny MA. Incidence and admission rates for severe malaria and their impact on mortality in Africa. Malar J. 2017;16(1):1.

25. Zambia Statistics Agency, Ministry of Health (MOH) Zambia, and ICF. 2019. Zambia Demographic and Health Survey 2018. Lusaka and Rockville: Zambia Statistics Agency, Ministry of Health, and ICF.

26. Bassat $Q$, Mulenga $M$, Tinto H, Piola P, Borrmann S, Menéndez C, et al. Dihydroartemisinin-piperaquine and artemether-lumefantrine for treating uncomplicated malaria in African children: a randomised, non-inferiority trial. PLoS One. 2009:4(11):e7871.

27. Nambozi M, Van Geertruyden JP, Hachizovu S, Chaponda M, Mukwamataba $D$, Mulenga M, et al. Safety and efficacy of dihydroartemisinin-piperaquine versus artemether-lumefantrine in the treatment of uncomplicated plasmodium falciparum malaria in Zambian children. Malar J. 2011;10:50.

28. Four Artemisinin-Based Combinations ( $4 A B C$ ) Study Group. A head-to-head comparison of four artemisinin-based combinations for treating uncomplicated malaria in African children: a randomized trial. PLoS Med. 2011;8(11):e1001119.

29. Hamainza B, Masaninga F, Moonga H, Mwenda M, Chanda-kapata P, Chalwe $V$, et al. Therapeutic efficacy of artemether-lumefantrine on treatment of uncomplicated plasmodium falciparum mono-infection in an area of high malaria transmission in Zambia. Malar J. 2014;13:430.

30. Pekyi D, Ampromfi AA, Tinto H, Traoré-Coulibaly M, Tahita MC, Valéa I, et al. Four Artemisinin-based treatments in African pregnant women with malaria. N Engl J Med. 2016;374(10):913-27.

31. Depoortere E, Guthmann JP, Pressé J, Sipilanyambe N, Nkandu E, Balkan S, et al. Efficacy and effectiveness of the combination of sulfadoxine/ pyrimethamine and a 3-day course of artesunate for the treatment of uncomplicated falciparum malaria in a refugee settlement in Zambia. Tropical Med Int Health. 2005;10(2):139-45.
32. Chanda P, Hawela M, Kango M, Sipilanyambe N. Assessment of the therapeutic efficacy of a paediatric formulation of artemether-lumefantrine (Coartesiane) for the treatment of uncomplicated plasmodium falciparum in children in Zambia. Malar J. 2006;5:75.

33. Yeka A, Tibenderana J, Achan J, D'Alessandro U, Talisuna AO. Efficacy of quinine, artemether-lumefantrine and dihydroartemisinin-piperaquine as rescue treatment for uncomplicated malaria in Ugandan children. PLoS One. 2013;8(1):e53772.

34. Verret WJ, Arinaitwe E, Wanzira H, Bigira V, Kakuru A, Kamya M, et al. Effect of nutritional status on response to treatment with artemisinin-based combination therapy in young Ugandan children with malaria. Antimicrob Agents Chemother. 2011;55(6):2629-35.

35. Depoortere E, Guthmann JP, Sipilanyambe N, Nkandu E, Fermon F, Balkan S, et al. Adherence to the combination of sulphadoxine-pyrimethamine and artesunate in the Maheba refugee settlement, Zambia. Tropical Med Int Health. 2004;9(1):62-7.

36. Aspler A, Menzies D, Oxlade O, Banda J, Mwenge L, Godfrey-Faussett P, et al. Cost of tuberculosis diagnosis and treatment from the patient perspective in Lusaka, Zambia. Int J Tuberc Lung Dis. 2008;12(8):928-35.

37. World Health Organization. Health Service Delivery Costs Geneva, Switzerland 2010. Available from: https://www.who.int/choice/costeffectiveness/inputs/health_service/en/. Cited 2019 February 11.

38. The World Bank. Zambia 2019. Available from: https://data.worldbank.org/ country/zambia. Cited 2019 Feb 11

39. Chanda P, Castillo-Riquelme M, Masiye F. Cost-effectiveness analysis of the available strategies for diagnosing malaria in outpatient clinics in Zambia. Cost Eff Resour Alloc. 2009;7:5.

40. Chanda P, Masiye F, Chitah B, Sipilanyambe N, Hawela M, Banda P, et al. A cost-effectiveness analysis of artemether lumefantrine for treatment of uncomplicated malaria in Zambia. Malar J. 2007;6:21.

41. Comfort AB, van Dijk JH, Mharakurwa S, Stillman K, Gabert R, Korde S, et al. Hospitalizations and costs incurred at the facility level after scale-up of malaria control: pre-post comparisons from two hospitals in Zambia. Am J Trop Med Hyg. 2014;90(1):20-32.

42. Chanda P, Hamainza B, Moonga HB, Chalwe V, Banda P, Pagnoni F. Relative costs and effectiveness of treating uncomplicated malaria in two rural districts in Zambia: implications for nationwide scale-up of home-based management. Malar J. 2011;10:159.

43. Hamainza B, Moonga $H$, Sikaala CH, Kamuliwo M, Bennett A, Eisele TP, et al. Monitoring, characterization and control of chronic, symptomatic malaria infections in rural Zambia through monthly household visits by paid community health workers. Malar J. 2014;13:128.

44. Worldwide Antimalarial Resistance Network. WWARN tracker 2019. Available from: https://www.wwarn.org/. Cited 2019 Feb 11

45. United States Treasury. Current Rates 2019. Available from: https://fiscal. treasury.gov/reports-statements/treasury-reporting-rates-exchange/. Cited 2019 Feb 11.

46. The World Bank. Inflation, consumer prices Zambia 2019. Available from: https:// data.worldbank.org/indicator/FP.CPI.TOTL.ZG?locations=ZM. Cited 2019 Feb 11.

47. World Health Organization. Responding to antimalarial drug resistance 2018. Available from: https://www.who.int/malaria/areas/drug_resistance/ overview/en/. Updated 20 April 2018; cited 2019 Jan 4.

48. Knoema. Zambia - Total population aged 0-4 years 2018. Available from: https://knoema.com/search?query=Zambia\%20population\%200-4.

49. Kiefer S, Patouillard E, Palafox B, Tougher S, Mpasela F, Goodman C, et al. A Qualitative Assessment of the Private Sector Antimalarial Distribution Chain in Zambia, 2009. Nairobi: ACTwatch project; 2012.

50. Global Pharma Health Fund. The GPHF-minilab: protection against counterfeit medicines. Giessen: Global Pharma Health Fund. Available from: https://www.gphf.org/en/minilab/. Cited 2020 January 15.

51. Hamooya BM, Chongwe G, Dambe R, Halwiindi H. Treatment-seeking behaviour for childhood fever among caretakers of Chivuna and Magoye rural communities of Mazabuka District, Zambia: a longitudinal study. BMC Public Health. 2016;16(1):762.

52. Bright $T$, Felix L, Kuper $H$, Polack $S$. A systematic review of strategies to increase access to health services among children in low and middle income countries. BMC Health Serv Res. 2017;17(1):252.

53. Pisani E. How moves towards universal health coverage could encourage poor quality drugs: an essay by Elizabeth Pisani. BMJ. 2019;366:15327.

54. Xie Y. Values and limitations of statistical models. Res Soc Stratif Mobil. 2011; 29(3):343-9. 
55. Gomez-Ramirez J, Sanz R. On the limitations of standard statistical modeling in biological systems: a full Bayesian approach for biology. Prog Biophys Mol Biol. 2013;113(1):80-91.

\section{Publisher's Note}

Springer Nature remains neutral with regard to jurisdictional claims in published maps and institutional affiliations.

- fast, convenient online submission

- thorough peer review by experienced researchers in your field

- rapid publication on acceptance

- support for research data, including large and complex data types

- gold Open Access which fosters wider collaboration and increased citations

- maximum visibility for your research: over $100 \mathrm{M}$ website views per year

At $\mathrm{BMC}$, research is always in progress. 